\title{
Recomendación sobre pruebas de función pulmonar durante la pandemia por coronavirus COVID-19. Junio 2020
}

\author{
CECILIA ALVAREZ G.*, GISELLA BORZONE T.*, JUAN CÉSPEDES G*., RAÚL CORRALES V.*, \\ MÓNICA GUTIÉRREZ C.*, MÓNICA GUTIÉRREZ N*. y PATRICIA SCHONFFELDT G.*
}

\section{Advice Regarding COVID -19 Pandemic for Pulmonary Function Laboratories. SERChile. June 2020}

Existe preocupación por el riesgo de transmisión de SARS-CoV-2 en el contexto de la realización de pruebas de función pulmonar, debido a la posibilidad de tos y formación de gotitas en torno a estos procedimientos, agravado por la alta concurrencia de pacientes con enfermedad pulmonar crónica que acuden para evaluación con estos exámanes. Quedan muchas incógnitas sobre la posibilidad de transmisión en este entorno y los datos están en evolución; sin embargo, los riesgos de transmisión pueden ser significativos y probablemente variar según la prevalencia del virus en la comunidad y la edad, la gravedad de la enfermedad pulmonar y la presencia de inmunosupresión.

En la práctica diaria habitualmente se toman precauciones para evitar infecciones cruzadas, las que estan descritas en todos los manuales y guias para realizar estos exámenes. Sin embargo, durante el brote actual de la enfermedad por coronavirus (COVID-19), estas medidas pueden ser insuficientes, dado la contagiosidad y potencial letalidad de este virus.

Por lo tanto, al igual que otras sociedades e instituciones ${ }^{1-5}$, recomendamos que mientras dure la pandemia, se suspendan todos los exámenes de función pulmonar de rutina, especialmente las pruebas de provocación bronquial tanto con metacolina como por ejercicio, la realizacion del test cardiopulmnar y el test de marcha de 6 minutos y se realicen solamente las pruebas requeridas para decisiones terapéuticas que no puedan ser diferidas, como por ejemplo riesgo quirúrgico en un paciente con patología oncológica, trasplantados $\mathrm{u}$ otros que requieran una decisión terapéutica in- mediata. Básicamente espirometrías y capacidad de difusión pulmonar.

En el caso de tener que realizar exámenes, se deben extremar las medidas para proteger tanto al personal como a las personas que se están evaluando.

Además de las medidas estándar, se debe:

- Hacer uso de filtros antibacterianos y antivíricos desechables de tal forma de evitar la aerolización durante la espiración. Es imprescindible que los filtros utilizados tengan validación de la eficiencia de filtración vírica a altos flujos espiratorios (600-700 1/min), de la repetibilidad y exactitud de las mediciones.

- Dejar el mínimo de objetos en el area del laboratorio.

- Limpiar las superficies con alcohol al 70\% u otro desinfectante similar después de atender a cada paciente, dejando 30 minutos sin paciente para poder desinfectar y ventilar la sala.

- Atender solo a un paciente por vez, evitando comenzar un nuevo paciente mientras se espera el efecto del broncodilatador en el primer paciente.

- En la sala sólo debe estar el examinador y el paciente.

- El personal que realiza las pruebas debe usar todos los elementos de protección personal (EPP): gorro desechable, lentes o escudo facial, máscara quirúrgica, delantal de mangas largas desechable, guantes y cubre zapatos desechables.

- Evitar que se junten pacientes en la sala de espera, programando muy bien las citaciones.

* Comisión de Función Pulmonar. Sociedad Chilena de Enfermedades Respiratorias.

11 de junio de 2020 
Se recomienda que todas estas medidas sean consensuadas con el grupo de infecciones intrahospitalarias de cada centro y que se revisen las actualizaciones que haremos a estas recomendaciones de acuerdo a la evolucion de la pandemia.

\section{Bibliografía}

1. GUTIÉRREZ CLAVERÍA M, BEROÍZA MT, BORZONE G, CAVIEDES I, CÉSPEDES J, GUTIÉRREZ NAVAS M, et al. Espirometría: Manual de procedimientos. SERChile 2018. Rev Chil Enferm Respir 2018;34 (3):171-88.

2. AMERICAN THORACIC SOCIETY. Advice Regarding COVID 19 For Pulmonary Function Laboratories. Disponible en: https://www.thoracic.org/professionals/ clinical-resources/disease-related-resources/pulmonary-function-laboratories.php.

3. ACOEM Advises Suspension of Routine Occupational Spirometry Testing During COVID-19 Pandemic. Disponible en: https://acoem.org/News/Press-Releases/ ACOEM-Advises-Suspension-of-Routine-Occupational-Spirometry-Testing-During-COVID-19-Pandemic.

4. THE THORACIC SOCIETY OF AUSTRALIA AND NEW ZEALAND. Peak Respiratory Bodies recommend suspension of lung function testing. Disponible en: https://www.thoracic.org.au/documents/item/1864.

5. SEPAR. Recomendaciones de prevención de infección por coronavirus en las unidades de función pulmonar de los diferentes ámbitos asistenciales: (Actualización de 20 de mayo 2020). Disponible en: https://drive.google. com/file/d/1DQgTeca76H1VtkDg6-KhPqb-kOmVoLk1/ view.
Correspondencia a:

Dra. Mónica Gutiérrez Clavería

Coordinadora Comisión de Función Pulmonar, Sociedad Chilena de Enferedades Respiratorias.

Email: mgancaroe@gmail.com 